\title{
As ações da RETEC no apoio ao desenvolvimento tecnológico de Minas Gerais: um estudo piloto ${ }^{1}$
}

Janete Fernandes Silva
Mestre em Ciência da Informação pela
Escola de Ciência da Informação da
Universidade Federal de Minas
Gerais;Professora universitária;
Consultora em Gestão da Informação e
do Conhecimento

Alessandra Fiorini de Carvalho

Bacharel em Biblioteconomia pela Escola de Ciência da Informação da Universidade Federal de Minas Gerais; Consultora em Gestão da Informação

Priscila Bueno de Souza
Graduanda em Biblioteconomia pela Escola de Ciência da Informação da Universidade Federal de Minas Gerais; Colaboradora do Instituto Euvaldo Lodi

\begin{abstract}
Este artigo tem por objetivo o estudo das classificações adotadas pela Rede de Tecnologia de Minas Gerais (RETEC/MG), visando identificar seus pontos fortes e fracos e propor melhorias para os atributos de classificação que apresentaram fragilidade. Buscou-se, ainda, conhecer o campo de atuação e estrutura da RETEC/MG, verificar sua participação no desenvolvimento e crescimento das indústrias e identificar os tipos de informação e serviços demandados à rede.
\end{abstract}

Palavras-chave: Rede de tecnologia de Minas Gerais; Demanda tecnológica; Informação tecnológica

Projeto de Desenvolvimento Tecnológico Industrial financiado pelo Conselho Nacional de Desenvolvimento Científico e Tecnológico - CNPq, processo 554793/2005-9 e apoiado pelo Instituto Euvaldo Lodi de Minas Gerais - IEL/MG. 


\section{The actions of the RETEC for supporting the technology development of Minas Gerais - a pilot study}

The objective of this article was to analyze the types of classification adopted by the Technology Net of Minas Gerais (RETEC/MG). It aims to identify the strong and weak points of the classification, and also to propose improvements for the attributes that showed fragilities. We attempted to describe the field of activity and the structure of RETEC/MG, to verify its participation in the development and growth of the industries and, also, to identify the types of information and services that are demanded to the net.

Recebido em 10.04.2007 Aceito em 06.03.2008

\section{Introdução}

As empresas brasileiras estão enfrentando um ambiente cada vez mais competitivo, que vem impondo, de maneira desafiadora, o crescimento da capacidade de inovação tecnológica e de gestão. Os aspectos qualidade, produtividade e competitividade tornam-se cada vez mais dependentes da capacidade de incorporação da inovação em produtos, processos e gestão. A necessidade de identificar e implementar conjuntos de instrumentos de fomento e de marco legal gera condições operacionais coerentes em resposta às demandas informacionais determinadas pelas indústrias.

Todo esse contexto exige uma série de ações diretas nos segmentos empresarial e industrial, considerando-se as particularidades das organizações, dos setores, das cadeias produtivas e, ainda, das situações locais em que as organizações se inserem (MINISTÉRIO DE CIÊNCIA E TECNOLOGIA, 2003).

Para agilizar e alavancar essas ações em direção ao desenvolvimento de produtos e serviços inovadores, o Instituto Euvaldo Lodi Nacional promove a consolidação e implantação da Rede de Tecnologia do Setor Industrial Brasileiro (RETEC/NC), que tem por missão integrar as Redes de Tecnologia (RETEC) regionais. Hoje, os estados que compõem a Rede são: Amazonas, Bahia, Ceará, Minas Gerais e Paraná. Ainda está sendo negociada a participação dos seguintes estados: Paraíba, Pernambuco, Rio de Janeiro, Rio Grande do Sul, Santa Catarina, São Paulo e Tocantins, além do Distrito Federal ${ }^{2}$.

2 INSTITUTO Euvaldo Lodi Nacional. Proposta de organização da RETEC Nacional. Brasília: IEL, 2004. 23 p. 
O objeto de investigação deste trabalho está fundamentado na Rede localizada no estado de Minas Gerais, que tem como proposta de atuação promover a integração da oferta e da demanda tecnológica entre os diversos agentes econômicos, sociais e institucionais; contribuir para o incremento de negócios tecnológicos; realizar ações de incentivo e desenvolvimento à pesquisa aplicada para as empresas; mobilizar as empresas para o desenvolvimento das competências em pesquisa, tecnologia e inovação, em busca de soluções tecnológicas para a indústria; e sensibilizar a classe empresarial para a capacitação e o desenvolvimento tecnológico, tendo como meta o aumento da competitividade de suas empresas.

Este artigo tem como ponto central a análise dos tipos de serviços e informações tecnológicos demandados por empresas e pessoas físicas do estado de Minas Gerais à RETEC, assim como de suas principais ações e resultados. Para a execução desta pesquisa, foi necessário realizar um recorte temporal. O banco de dados da RETEC/MG é composto de 4.700 demandas referentes a serviços e informações tecnológicos, registradas no período de 2002 a 2006. Deste universo, foram utilizados dados referentes ao segundo semestre de 2006, o que compreendeu seis meses e 497 demandas.

A busca da compreensão de como se encontra estruturada a RETEC/MG, bem como da sua importância para o desenvolvimento das indústrias mineiras, norteou este artigo. Seguem a esta introdução os seguintes itens: "Inovação, classificação e demanda: aspectos conceituais"; "Rede de Tecnologia do estado de Minas Gerais RETEC/MG: aspectos estruturais"; "classificação das demandas da RETEC/MG: processo de transição"; "Caracterização e tipos das demandas encaminhadas à RETEC/MG; e "Considerações finais".

\section{Inovação, classificação e demanda: aspectos conceituais}

No atual cenário vivenciado pelas organizações, a Lei de Inovação surge como um instrumento que contribui para alavancar as parcerias entre as instituições de pesquisa, de ensino e indústrias. É função da RETEC/MG promover a intermediação entre as indústrias (demandantes) e os centros de competências (ofertantes de informação e tecnologia), de modo a estreitar as relações entre ambas. O seu papel vai ao encontro das diretrizes traçadas na Lei, podendo servir de importante fornecedora de indicadores tecnológicos e econômicos capazes de subsidiar a política de inovação. Estes indicadores poderão, ainda, sinalizar as regiões mais fragilizadas e aquelas que se encontram em estágio de desenvolvimento mais avançado, permitindo às instituições privadas e públicas definirem estratégias e diretrizes direcionadas, segundo a vocação de cada uma.

Cabe reforçar que a Lei de Inovação - Lei 10.973, de 2 de dezembro de 2004 (BRASIL, 2004) - estabelece medidas de incentivo à inovação e à 
pesquisa científica e tecnológica no ambiente produtivo, com vista à capacitação, ao alcance da autonomia tecnológica e ao desenvolvimento industrial do país.

A Lei oferece abertura e permite às instituições científicas e tecnológicas a criação de mecanismos de gestão em sua relação com as empresas, principalmente de base tecnológica, por meio de procedimentos de três naturezas: estímulo à inovação, flexibilizando atividades e relações das instituições científicas e tecnológicas; estímulo à gestão da inovação, estabelecendo regimes de comercialização das inovações científicas e tecnológicas; e estímulo à inovação nas empresas, a partir da criação de mecanismos capazes de favorecer o ambiente de inovação empresarial (ROMERO, 2005).

De acordo com Matias (2003, p. 02), "o sucesso da inovação depende, em grande parte, da capacidade de aplicação contínua de novo conhecimento por parte dos diversos atores". Assim, torna-se necessário melhorar, de forma eficaz, a dinâmica com que estes produzem e difundem a informação, o conhecimento e as competências essenciais, de modo a contribuir para uma cultura de inovação.

Cabe esclarecer que a tecnologia só passa a ser uma inovação quando sai da fase de uma nova idéia e de produto acabado e transcende para a fase da comercialização (SILVA, 2000). Para Mueser (1985), citado por Escosteguy e Cabral (1996), "entende-se que a inovação tecnológica é uma nova idéia, um evento técnico descontínuo, o qual, após certo período de tempo é desenvolvido ao ponto em que se torna prático e usado com sucesso". Para que o sucesso da inovação ocorra é necessário um processo de gestão de informação e do conhecimento eficaz.

Há muito se discute sobre o tema "informação para a inovação". Esta é uma questão chave no processo de mudança e competitividade. A informação com foco tecnológico, que representa todo tipo de conhecimento relacionado ao modo de fazer um produto ou prestar um serviço, requer conhecimentos de natureza científica, empírica ou intuitiva. Nesta perspectiva, a informação para a inovação tem um caráter estratégico no planejamento das atividades das indústrias, o que envolve as relações interpessoais, os processos técnicos e gerenciais, o capital intelectual, a prospecção de tecnologia e a reestruturação das organizações diante das constantes mudanças do meio externo.

Devido às constantes interferências ambientais a que as organizações estão submetidas no dia-a-dia, os gestores das RETECs regionais não podem perder de vista a meta de subsidiá-las com informações que lhes permitam aumentar sua competitividade, não se esquecendo de quão complexo é o procedimento pelo qual a informação é incorporada nos processos produtivos e de gestão dos segmentos industriais.

Inúmeras foram as experiências conduzidas no Brasil, no campo da informação tecnológica, com resultados representativos, embora limitados. Estas experiências devem servir de referência para a Rede de Tecnologia do Setor Industrial Brasileiro, de forma a não se limitar apenas à intermediação entre demandante e ofertante, mas constituir-se em uma 
gestora de informações que agregue valor às atividades da indústria brasileira e seja um catalisador dos elementos que condicionam 0 processo de inovação.

Pretende-se, aqui, apresentar como as demandas feitas à RETEC/MG são classificadas e qual a importância de se definir com qualidade e assertividade os grupos de classificação.

A classificação adotada para classificar as demandas da RETEC/MG é a do tipo facetada, por permitir o agrupamento por facetas ou classes às demandas. De acordo com Foskett (1996), citado por Araújo (2006, p.128), para a elaboração de um sistema de classificação facetado, devem ser desempenhadas as seguintes atividades:

a) estudo cuidadoso da literatura sobre o assunto para determinar suas linhas gerais e o seu desenvolvimento;

b) análise do conteúdo do assunto, determinação de suas facetas;

c) nas facetas, seguindo uma seqüência útil, listagem dos focos que as compõem;

d) determinação da ordem de citação (ordem de precedência ou prioridade das facetas), que é aplicada quando se faz a síntese para assuntos compostos;

e) estudo da disposição das facetas dentro do esquema, que deverá mostrar claramente onde um assunto, simples ou composto, poderá ser encontrado.

Diante do exposto, percebe-se a importância de um sistema de classificação que permita a organização especializada e sistematizada das demandas.

Entende-se por demanda de informação, neste artigo, as realizadas pelo usuário em um sistema de informação e que podem ser registradas. Desta forma, pode-se dizer que a classificação de demanda de informação visa à organização e à ordenação de um conjunto de demandas em agrupamentos menores, a partir de características semelhantes e de suas diferenças.

\section{A Rede Tecnológica do estado de Minas Gerais - RETEC/MG: aspectos estruturais}

Em outubro de 2002, o Instituto Euvaldo Lodi do Estado de Minas Gerais (IEL/MG), por intermédio da Gerência de Informação e Projetos Tecnológicos (GIPT), inaugurou a RETEC/MG, cujos objetivos são: oferecer serviços de forma a integrar e interpretar demandas das indústrias locais; e oferecer soluções de melhorias e inovações em gestão, processos e produtos, contribuindo para a capacitação, competitividade e desenvolvimento da indústria mineira. Para a oferta dessas soluções, a RETEC/MG passou a disponibilizar serviços de consultoria, respostas técnicas e administrativas, relatórios estatísticos, tendo como 
preocupação principal a qualidade das demandas provenientes do mercado, de forma a diferenciá-las daquelas similares.

Desde 2005, a RETEC/MG aprimora suas atividades junto à comunidade empresarial, oferecendo atendimento aos empresários em questões tecnológicas, priorizando as demandas tecnológicas e, por intermédio do programa Apoio à Melhoria e Inovação Tecnológica (AMITEC), proporcionando fomento à inovação e a projetos tecnológicos. Com isso, passou a incluir em suas atividades a disponibilização de subsídios financeiros para custear os serviços resultantes das demandas geradas por seus usuários, desde que aprovados pelo Comitê de Investimento do AMITEC.

Cabe salientar que o AMITEC é um programa criado pelo IEL/Sistema FIEMG, em conjunto com a Fundação de Amparo à Pesquisa do Estado de Minas Gerais (FAPEMIG) e o Serviço Brasileiro de Apoio às Micro e Pequenas Empresas de Minas Gerais (SEBRAE/MG), e tem como principal objetivo estimular a melhoria e a inovação tecnológica das empresas do estado de Minas Gerais. Oferece subsídio financeiro para as empresas que solicitam serviços de informação, suporte, consultoria e inovação tecnológica através da Rede. As demandas referentes a serviços de informação, suporte e consultoria tecnológica são atendidas por ordem de entrada, com aprovação imediata pela equipe da RETEC/MG. Caso a demanda seja de inovação tecnológica, é solicitado à empresa o preenchimento de um formulário padrão (com informações sobre o projeto) que é analisado pelo Comitê de Investimentos do Programa AMITEC. As linhas de ação e as aplicações de subsídios são apresentadas a seguir:

- Informação tecnológica - o subsídio é de 100\%;

- Suporte tecnológico - o subsídio é de 70\%;

- Consultoria em: diagnóstico/parecer; desenvolvimento de projetos tecnológicos; e melhoria em processos, produtos, máquinas e equipamentos - o subsídio para cada é de $70 \%$;

- Inovação tecnológica - o subsídio é de $70 \%$.

As empresas que solicitam subsídios ao AMITEC e que se encontram nas linhas de ações que recebem $70 \%$ de subsídio devem, em contrapartida, participar com $30 \%$ de recursos, sendo $10 \%$ financeiro e $20 \%$ econômico.

Nesse sentido, a RETEC/MG tornou-se um importante instrumento para o processo de inovação tecnológica, contribuindo para o estímulo, capacitação e iniciativa das empresas na busca de aprimoramento contínuo em sua atividade.

Além do acesso via internet, a estrutura operacional da RETEC/MG contempla uma rede de alta capilaridade, constituída de federações e sindicatos da indústria, Serviço Nacional de Aprendizagem Industrial (SENAI), Serviço Brasileiro de Apoio às Micro e Pequenas Empresas 
(SEBRAE), centros de pesquisas, universidades e empresas de consultorias, dentre outros, o que permite uma abrangência única.

A estrutura adotada pela RETEC/MG para classificar uma demanda é a seguinte:

- Classificando a demanda: ao fazer a demanda, o cliente a classifica de acordo com as opções disponíveis no sistema, em função do tipo, objetivo e enfoque. Em seguida, por meio de uma descrição livre, apresenta a sua necessidade. A classificação tem por objetivo auxiliar nas estatísticas e atender aos seguintes requisitos:

1. Natureza: quanto à informação ou quanto ao serviço.

2. Serviço demandado: neste momento, o cliente determina a opção que está relacionada com a descrição da demanda. Cabe ressaltar que este tópico está intrinsecamente relacionado à determinação da natureza.

3. Objetivo da demanda: finalidade da demanda solicitada.

4. Enfoque da demanda: foco em que a demanda se destina.

5. Abrangência: delimitação do tempo e da área geográfica relacionada a determinado assunto. Quanto à abrangência temporal, determina-se o limite temporal para a realização da busca de informação sobre o assunto em pauta (por exemplo: de janeiro de 2000 a dezembro de 2005). Quanto à abrangência geográfica, o cliente informa se o assunto compreende uma cidade, um estado ou um país. Já quanto ao grau de conhecimento, busca-se levantar e identificar o grau de conhecimento do cliente em relação ao assunto, para determinar o nível de abrangência ou de aprofundamento na resposta a ser oferecida.

- Cadastro do usuário ofertante: cadastro de pessoas competentes em campos diversos do conhecimento que ajudarão nas respostas às demandas solicitadas.

- Cadastro da instituição: a RETEC/MG oferece aos seus usuários a possibilidade de acessar o cadastro da instituição na qual estão inseridos, o que permite o vínculo do usuário com a instituição na Rede.

- Sistema de gestão de atendimento às demandas: para atender com precisão, clareza e objetividade a uma demanda, a RETEC/MG dispõe de um sistema de gestão que permite o controle, a organização e o tratamento das demandas. O sistema oferece um ambiente em que é possível gerenciar o fluxo de atendimento, permitindo identificar com quem, onde, quando e em que fase se encontra a solução, sendo ainda possível rastrear todas as etapas desde a chegada da demanda até o recebimento da resposta por parte do demandante. 
- Processo de seleção/classificação das demandas: é utilizado para controlar os tipos de demandas e identificar as entidades que as realizam. Existem quatro tipos de categorias para a realização da classificação: categoria $A$, que representa as indústrias e suas entidades de classe, cujas demandas geram serviços e produtos; categoria $B$, que corresponde às entidades que não são indústrias, mas geram serviços; categoria $C$, que compreende as entidades que não são da indústria e que não geram serviços, mas fazem demandas com foco tecnológico; e categoria $D$, que corresponde às demandas de conteúdo não tecnológico.

A determinação das categorias surgiu devido à necessidade de se identificar e priorizar as demandas industriais com caráter tecnológico e de inovação. Assim, é possível dimensionar e direcionar esforços na resposta que surge dentro dos Arranjos Produtivos Locais (APLs), apoiados pelo Instituto Euvaldo Lodi (IEL) e nas demais demandas da indústria mineira.

No o futuro, a RETEC/MG, que tem à sua frente um mercado altamente competitivo, deverá se posicionar de forma mais estratégica, oferecendo vantagens como: dinâmica propiciada pela Rede; capilaridade de atuação; relacionamentos dos Sistemas Confederação e Federação das Indústrias; e maior confiabilidade e confidencialidade dos dados. Como visão para o futuro, tem como meta tornar-se referência no provimento de soluções tecnológicas, aqui entendidas de maneira ampla, no nível de processo, produto e gestão; o que requer ações para a obtenção de informações de conteúdo relevante, de maneira ágil e eficaz; a prestação de serviços requeridos nas demandas; e a criação de mecanismos de acompanhamento e monitoramento que os clientes reconheçam como adequados e estratégicos.

Diante dessa nova perspectiva, surge por parte da equipe de gestão da informação e do conhecimento (GIC) a necessidade de melhorar e aprimorar o processo e a metodologia de classificação das demandas, pois o definido no início da sua atuação encontra-se obsoleto e ineficaz.

\section{Classificação das demandas da RETEC/MG: processo de transição}

No passado, o demandante tinha à sua disposição classificações que hoje não atendem mais às necessidades da RETEC/MG. As classificações anteriores eram generalistas e, muitas vezes, não representavam 0 conteúdo da demanda, o que gerava distorções na caracterização, integridade, clareza e objetividade dos dados descritos, dificultando a análise quantitativa e qualitativa. Este grupo de classificações foi adotado de 2002 até o final do primeiro semestre de 2006, quando, a partir de um estudo minucioso realizado pela equipe de gestão da informação e do conhecimento (GIC), representada pela GIPT, concluiu-se que havia a necessidade de redefinir as classificações. A proposta foi uma ação piloto de adequação das classificações, de forma a atender às necessidades 
atuais da Rede. A redefinição das classificações, um processo de transição, permitiu uma melhor identidade e co-relação do conteúdo descrito com as novas classificações, proporcionando maior assertividade nas respostas e ações da equipe técnica.

Durante o processo de transição, a equipe de GIC buscou também averiguar a adequação e a aceitação das novas classificações pelos clientes, técnicos e supervisor da RETEC/MG. Observou-se uma grande aceitação dos grupos que compõem a Rede, assim como ganhos relacionados: à facilidade no desenvolvimento e atuação; ao direcionamento dos esforços da equipe; à identificação dos serviços com foco em inovação, em melhoria e em desenvolvimento tecnológico; à classificação por parte do demandante; à identificação das competências técnicas que respondem às demandas; à elaboração de relatórios quantitativos com dados mais direcionados e confiáveis; e à identificação de gargalos e oportunidades tecnológicas no estado de Minas Gerais.

Com a adoção da nova classificação, percebeu-se que o demandante passou a ter mais facilidade para classificar as demandas, acarretando em menor interferência do supervisor no ajuste das classificações de acordo com os conteúdos.

No tópico seguinte, serão apresentados os dados extraídos da nova proposta. O delineamento temporal cobre o segundo semestre de 2006. Com este estudo piloto, foi possível extrair dados como: regiões de Minas Gerais que mais demandam informação e que demandam mais serviços; tipos de informações mais demandadas e principais serviços subsidiados com recursos do AMITEC; dentre outros cruzamentos, como apresentado a seguir

\section{Demandas tecnológicas encaminhadas à RETEC/MG: caracterização e tipos}

O demandante, após o seu cadastramento, pode acessar imediatamente a Rede e fazer uso dos serviços, registrando suas demandas. Este acesso pode se dar quantas vezes o usuário necessitar, sendo que para cada demanda haverá uma resposta, com tratamento específico e foco individualizado e assertivo. Nesta fase, uma das dificuldades enfrentadas pelos técnicos e supervisor da RETEC/MG está relacionada à interpretação clara da demanda, pois, como o contato com o usuário é realizado via Internet, ocorrem muitas perdas de informações, por falta de uma descrição precisa e objetiva na hora de compor o texto, por exemplo: "Gostaria de informações sobre o processo de reciclagem". Veja que nada foi informado sobre o tipo de material que se deseja reciclar. Dessa forma, a resposta à demanda pode possuir lacunas e não ser precisa. Para que o problema seja solucionado, os técnicos ou o supervisor devem entrar em contato pelo sistema RETEC/MG ou por telefone para obterem as informações faltosas. Na fase de atendimento por telefone, podem ocorrer perdas de informações, por este se dar de maneira informal e, algumas vezes, pelo fato do conteúdo das informações levantadas não ser registrado e nem armazenado, sendo 
registrado apenas o fluxo de atividades. Torna-se necessário realizar um estudo mais aprofundado sobre o controle e o fluxo do conteúdo proveniente de atendimentos informais. O demandante, ao fazer sua solicitação, deve classificá-la para, posteriormente, a equipe da RETEC/MG conferir se a classificação ocorreu de forma correta.

A equipe, após a redefinição das classificações, buscou, a partir de um recorte temporal, apresentar algumas possibilidades de cruzamentos. A apresentação e análise dos dados ocorreram a partir do registro das demandas e dos meses em que foram registradas no sistema. O universo estudado foi o segundo semestre de 2006, correspondente aos meses de julho a dezembro. Os dados analisados encontram-se na Tabela 1 (TAB.1).

TABELA 1- Demandas à RETEC/MG segundo natureza da demanda, tipo de pessoa (física/jurídica) e enfoque. 2006 - $2^{\circ}$ semestre

\begin{tabular}{|c|c|c|c|c|c|c|c|c|c|c|c|c|}
\hline \multirow[b]{2}{*}{ Mês } & \multicolumn{2}{|c|}{ Naturexa } & \multicolumn{2}{|c|}{ Pessoa } & \multicolumn{4}{|c|}{ Enfogue } & \multicolumn{4}{|c|}{ Classificação } \\
\hline & Informação & Serviço & Fisica & Juridica & Admin & $\begin{array}{l}\text { Econômico/ } \\
\text { Financeiro }\end{array}$ & $\begin{array}{c}\text { Juridico/ } \\
\text { legislaçãa }\end{array}$ & Técnico & $\begin{array}{c}\text { Tipo } \\
\text { A }\end{array}$ & $\begin{array}{c}\text { Tipo } \\
\text { C }\end{array}$ & $\begin{array}{c}\text { T'po } \\
\text { D }\end{array}$ & $\begin{array}{l}\text { Não } \\
\text { consta }\end{array}$ \\
\hline Julho & 59 & 5 & 50 & 14 & 8 & 1 & 3 & 52 & 4 & 23 & 33 & 4 \\
\hline Agosto & 72 & 72 & 58 & 86 & 8 & 4 & 49 & 83 & 65 & 19 & 47 & 13 \\
\hline Setembro & 47 & 68 & 50 & 65 & 4 & 11 & 18 & 82 & 31 & 10 & 35 & 39 \\
\hline Outubro & 50 & 22 & 39 & 33 & 21 & 10 & 7 & 34 & 16 & 9 & 33 & 14 \\
\hline Novembro & 50 & 11 & 33 & 28 & 14 & 9 & 2 & 36 & 9 & 16 & 30 & 6 \\
\hline Dezembro & 31 & 10 & 30 & 11 & 6 & 19 & 3 & 13 & 6 & 3 & 26 & 6 \\
\hline Total & 309 & 188 & 260 & 237 & 61 & 54 & 82 & 300 & 131 & 80 & 204 & 82 \\
\hline
\end{tabular}

FONTE - Base de dados da Rede de Tecnologia de Minas Gerais, 2006.

A RETEC/MG respondeu a 497 demandas no período em análise, sendo 260 provenientes de pessoas físicas e 237 de pessoas jurídicas. Deste universo, 309 demandas foram classificadas na natureza informação e 188 na natureza serviços. Agosto foi o mês em que mais se demandou informações (72), seguido de julho (59). Quanto a serviços, agosto continua na liderança, com 72 demandas, seguido de setembro, com 68 demandas. Dezembro foi o mês com menos demandas, talvez pelo fato de ser um período de férias coletivas tanto do sistema FIEMG quanto dos sindicatos. Salienta-se que essa tendência não se aplica a todas as regiões ou segmentos do estado. Por exemplo, o Arranjo Produtivo Local de Fogos de Artifício experimenta, neste período, intenso processo de produção. As demandas classificadas na natureza informação sobressaem em relação ao número de demandas classificadas na natureza serviço, talvez por ser recente o apoio financeiro do AMITEC às demandas referentes a serviços com foco tecnológico. A tendência é que este número cresça.

O processo interno de classificação de demandas por tipo, A, B, C, $D$, conforme anteriormente especificado, visa identificar as demandas 
potenciais de geração de serviços tecnológicos, separando-as das demandas que não possuem caráter tecnológico. Esta classificação é muito importante para direcionar os esforços e as ações da GIPT e do IEL no apoio às indústrias do estado de Minas Gerais. Dentro do universo estudado não houve demandas classificadas pelo tipo B, por esta corresponder às entidades que não são indústrias. Quanto às demandas do tipo $C$, não se referem à indústria, não demandam serviço, mas demandam informação tecnológica, representando 80 demandas do universo investigado. Já as demandas do tipo $D$ correspondem às demandas de conteúdo não tecnológico, sendo que 204 demandas foram classificadas por este tipo. Por outro lado, 82 demandas não receberam classificação por parte da equipe da RETEC/MG. Desta forma, focar-se-á na análise das demandas classificadas no tipo $A$, que representam as indústrias e suas entidades de classe e geram serviços e produtos, podendo ser apoiadas pelo programa AMITEC. Os dados apresentados estão estritamente relacionados às demandas de serviços provenientes da Rede.

Do universo de 188 demandas referentes à natureza serviços, 131 foram classificadas no tipo $A$, sendo que $84 \%$ geraram serviços apoiados pelo AMITEC. Muitas vezes, este tipo de classificação está relacionado a: melhoria de processo, desenvolvimento de produto, parecer e análise técnica e diagnóstico de teor tecnológico, dentre outros serviços. Percebese a importância da RETEC/MG na identificação de projetos que possam contribuir para o desenvolvimento da indústria mineira. No universo dos $84 \%$ de indústrias apoiadas pelo programa, torna-se importante realizar estudos in loco para averiguar os ganhos da indústria com o apoio AMITEC. Os dados apresentados a seguir foram extraídos dos relatórios técnicos realizados pelos consultores contratados, os quais se encontram sob a responsabilidade e guarda da GIPT. Trata-se de descrições de alguns projetos beneficiados pela rede e agrupados por setor. Por questão de sigilo, os dados das empresas não serão divulgados.

- Projetos beneficiados - setor de eficiência energética: a empresa 1 atua no mercado de transformação, fabricação de estruturas metálicas em aço e caldeiraria em geral. Com os resultados, economizou aproximadamente $R \$ 2.665,00$ por mês em sua conta de energia elétrica, o que corresponde a $43 \%$ do total consumido, com o retorno do investimento em seis meses. A empresa 2 atua no mercado de máquinas e equipamentos: fabrica, fornece e instala retomadoras, empilhadeiras, transportadores de correias, guindastes, descarregadores de navios, máquina perfuratriz de túneis, caçambas, estruturas metálicas e sistemas de automação. Com os resultados, economizou aproximadamente $\mathrm{R} \$ 9.777,00$ por mês na conta de energia elétrica, ou seja, $31 \%$ do valor total, com um retorno do investimento em seis meses. A empresa 3 atua 
no mercado de siderurgia, desenvolvendo atividades de engenharia, projeto, fabricação e instalações "chave na mão", relativas a processos industriais e manuseio de materiais. A economia foi de aproximadamente $\mathrm{R} \$$ $7.456,00$ por mês na conta de energia elétrica, ou seja, $35 \%$ do valor total, com um retorno do investimento em sete meses. A empresa 4 atua no mercado de transformação, produzindo embalagens metálicas industriais para gêneros alimentícios, decorativas e promocionais. A economia foi de aproximadamente $R \$$ $10.333,00$ por mês na conta de energia elétrica, ou seja, $52 \%$ do valor total, com retorno do investimento em seis meses. A empresa 5 atua no mercado de química e petroquímica, sendo fabricante de lubrificantes para motores a gasolina/álcool e a diesel para transmissões, graxas e lubrificantes industriais, além de fluidos e produtos especiais. A empresa obteve economia de $\mathrm{R} \$$ 13.692.61 por mês na conta de energia elétrica, correspondendo a $18 \%$ do valor total, com retorno do investimento em seis meses. A empresa 6 atua no mercado automotivo, fabricando peças e acessórios para veículos automotores. A empresa conseguiu com o benefício a economia de $R \$ 83.769 .50$ por mês na conta de energia elétrica, ou seja, $20 \%$ do valor total, com um retorno do investimento em 24 meses. As seis empresas, com o apoio do AMITEC, realizaram as seguintes ações: ajuste do fator de potência; desligamento definitivo do transformador de 500 kVA; alteração tarifária e procedimento operacional para o horário de ponta; eliminação de vazamentos e otimização do sistema de ar comprimido; substituição dos componentes de iluminação; melhoria de processos; instalação do sistema de co-geração de energia; e correção do fator de potência;

- Projetos beneficiados - setor moveleiro: a empresa 1 atua no mercado de móveis, produzindo móveis domésticos em madeira, sem instalação. Os resultados obtidos com o investimento foram: redução do tempo de embalagem e aumento da produtividade; redução de custo e melhoria da qualidade da superfície dos móveis; criação de uma cultura de melhoria da qualidade, tanto por parte dos encarregados quanto dos colaboradores dos setores; padronização dos processos críticos, evitando empirismo e possíveis falhas; maior suporte do setor comercial ao setor de produção (produção puxada); aumento da autonomia dos setores e consecutiva agilidade no processo de tomada de decisão; e organização do tempo do colaborador 
envolvido no planejamento de controle de produção. A empresa 2 atua no mercado de fabricação de móveis em madeira e a empresa 3 atua no mercado de fabricação de móveis e outros produtos em madeira. Ambas alcançaram os seguintes resultados: redução do volume de estoques intermediários dentro da produção; redução da circulação de peças na produção; redução da movimentação de funcionários entre os setores; e melhor acompanhamento das atividades no processo fabril;

- Projetos beneficiados - setor automotivo: a empresa 1 atua no mercado automotivo e a empresa 2 atua no mercado de autopeças, produzindo estamparia de componentes automotivos, solda, perfilaria e ferramentaria. As empresas alcançaram os seguintes resultados com o benefício: adequação do produto às exigências do mercado; atendimento da legislação e normas específicas; atendimento de exigências de caráter ambiental; diferenciação do produto e/ou serviço; melhoria da posição no mercado; e redução dos impactos ambientais;

- Projetos beneficiados - setor de alimentos e bebidas: a empresa 1 atua no mercado de alimentos e bebidas. Os resultados alcançados foram: minimização de investimentos, por meio do programa de manutenção preventiva dos equipamentos, do programa de limpeza e educação de uso de equipamentos e do programa de conscientização de funcionários e clientes; criação de uma comissão interna de conservação de energia, que tem como uma de suas atividades o acompanhamento semanal do consumo; aquisição de equipamentos novos; o que gerou uma economia mensal de $\mathrm{R} \$ 1.229,22$.

Os dados obtidos dos relatórios técnicos mostram que com pequenos investimentos as empresas podem economizar na linha de produção, no consumo de energia e no atendimento às especificações da legislação de meio ambiente, como também produzir e fornecer com mais qualidade e alcançar novas fatias de mercado.

A próxima análise, na tabela 2 (TAB. 2), apresenta as demandas, segundo tipo de informação e serviço (veja conceitos referentes aos tipos, em anexo), classificando-as por microrregião. A classificação por microrregião do estado de Minas Gerais segue o padrão FIEMG. Esta classificação permitiu avaliar qual região do Estado demandou mais ou menos informações e serviços à RETEC/MG. Ainda, a classificação pode contribuir e ajudar o sistema FIEMG a dimensionar oportunidades e ameaças no momento presente e futuro. 
A tabela 2, a seguir, foi estruturada a partir do modelo matricial ${ }^{3}$.

TABELA 2- Demandas à RETEC/MG segundo tipo de informação e de serviço e micro-região de Minas Gerais. 2006 - $2^{\circ}$ semestre

\begin{tabular}{|c|c|c|c|c|c|c|c|c|c|c|c|c|c|}
\hline \multirow[b]{2}{*}{ Mic ro Regiāo } & \multicolumn{13}{|c|}{ Informações Solicitadas } \\
\hline & Insumo & $\begin{array}{c}\text { Linhas de } \\
\text { financiamento }\end{array}$ & $\begin{array}{l}\text { Normas } \\
\text { técricas } \\
\end{array}$ & \multicolumn{2}{|c|}{$\begin{array}{c}\text { Operações } \\
\text { Administrativas }\end{array}$} & Processo & \begin{tabular}{|c|}
$\begin{array}{c}\text { Produção e } \\
\text { controle }\end{array}$ \\
\end{tabular} & Produto & \multicolumn{2}{|c|}{$\begin{array}{l}\text { Propriedade } \\
\text { Intelectual }\end{array}$} & $\begin{array}{c}\text { Metrolo } \\
\text { gia }\end{array}$ & Outro & Total \\
\hline Metropolitana de BH & 4 & 42 & 1 & \multicolumn{2}{|c|}{2} & 13 & 6 & 14 & \multicolumn{2}{|c|}{1} & 2 & 3 & 88 \\
\hline Alto Paranaiba & 3 & $\ldots$. & $\ldots$. & \multicolumn{2}{|c|}{2} & 12 & 3 & 4 & \multicolumn{2}{|c|}{1} & $\ldots$. & 2 & 27 \\
\hline Norte & 1 & $\ldots$. & 1 & \multicolumn{2}{|c|}{3} & 5 & 4 & 6 & \multicolumn{2}{|c|}{1} & $\ldots .$. & 1 & 22 \\
\hline Pontal do Triângulo & $\ldots$ & $\ldots$ & $\ldots$ & \multicolumn{2}{|c|}{$\ldots}$. & 1 & $\ldots$ & 1 & \multicolumn{2}{|c|}{$\ldots}$. & $\ldots$. & $\ldots$. & 2 \\
\hline Rio Doce & 2 & $\ldots$ & $\ldots$ & \multicolumn{2}{|c|}{3} & 11 & 2 & 5 & \multicolumn{2}{|c|}{$\ldots}$. & $\ldots$. & $\ldots$ & 23 \\
\hline Sul & 9 & 11 & 4 & \multicolumn{2}{|c|}{6} & 19 & 7 & 21 & \multicolumn{2}{|c|}{$\ldots$} & $\ldots$ & 5 & 82 \\
\hline Vale do $A c ̧ O$ & 5 & $\ldots$. & 2 & \multicolumn{2}{|c|}{1} & 5 & $\ldots$ & 8 & \multicolumn{2}{|c|}{$\ldots}$. & $\ldots$. & $\ldots$ & 21 \\
\hline Vale do Paranaiba & 2 & $\ldots$ & $\ldots$ & \multicolumn{2}{|c|}{2} & 8 & 1 & 7 & \multicolumn{2}{|c|}{$\ldots$} & $\ldots$ & $\ldots$ & 20 \\
\hline Vale do Rio Grande & & $\ldots$ & $\ldots$. & \multicolumn{2}{|c|}{$\ldots}$. & 8 & $\ldots$ & 1 & \multicolumn{2}{|c|}{1} & $\ldots$ & $\ldots$ & 10 \\
\hline Zona da Mata & 1 & $\ldots$. & $\ldots$. & \multicolumn{2}{|c|}{$\ldots}$. & 10 & 1 & 1 & \multicolumn{2}{|c|}{$\ldots}$. & $\ldots$. & $\ldots$. & 13 \\
\hline Outros estados & & & & … & & & & 1 & &. & $\ldots .$. & $\ldots .$. & 1 \\
\hline TOTAL & 27 & 53 & 8 & \multicolumn{2}{|c|}{19} & 92 & 24 & 69 & \multicolumn{2}{|c|}{4} & 2 & 11 & 309 \\
\hline \multirow[b]{2}{*}{ Mir ro Regĩa } & \multicolumn{13}{|c|}{ Serviços Solizitados } \\
\hline & $\begin{array}{l}\text { Gestão da } \\
\text { Qualidade }\end{array}$ & $\begin{array}{c}\text { Capacitação } \\
\text { treinamento de } \\
\text { pessoal }\end{array}$ & \multicolumn{2}{|c|}{$\begin{array}{c}\text { Deserwolvimento e } \\
\text { melhoria de } \\
\text { processo }\end{array}$} & $\begin{array}{c}\text { Desenv } \\
\text { mell } \\
\mathrm{pm}\end{array}$ & $\begin{array}{l}\text { Wimento e } \\
\text { woria de } \\
\text { oduto }\end{array}$ & $\begin{array}{l}\text { Parecere } \\
\text { análise } \\
\text { técrica }\end{array}$ & $\begin{array}{r}\text { Projet } \\
\text { tecnológ } \\
\text { de inowe }\end{array}$ & $\begin{array}{l}\text { os } \\
\text { icose } \\
\text { ação }\end{array}$ & $\begin{array}{l}\text { Pros } \\
\text { Tecr }\end{array}$ & $\begin{array}{l}\text { pecção } \\
\text { wológica }\end{array}$ & Outro & Total \\
\hline Metropolitana de BH & 10 & $\ldots$ & 3 & 4 & & 5 & 7 & 8 & & & 1 & 6 & 71 \\
\hline Alto Paranaiba & $\ldots$. & $\ldots$. & . & $\ldots$ & & $\ldots$. & $\ldots$. & $\ldots$. & & & $\ldots$. & 1 & 1 \\
\hline Centro Oeste & 1 & & 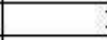 & 1 & & $\ldots$ & 58 & $\ldots .$. & & & $\ldots$. & $\ldots$ & 60 \\
\hline Norte & & 1 & 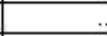 & 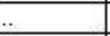 & & $\ldots$ & 1 & $\ldots$. & & & $\ldots$. & & 2 \\
\hline Fio Doce & $\ldots$. & $\ldots$ & . & ... & & $\ldots$ & $\ldots$ & $\ldots$ & & & $\ldots$. & 1 & 1 \\
\hline Sul & $\ldots$. & $\ldots$. & 7 & & & 3 & 7 & 17 & & & $\ldots$. & 2 & 35 \\
\hline Vale do $A c o$ & $\ldots$. & $\ldots$ & 2 & 2 & & $\ldots$. & $\ldots$ & $\ldots .$. & & & $\ldots$. & 2 & 4 \\
\hline Vale do Paranaiba & $\ldots$. & 1 & 2 & 2 & & $\ldots$. & $\ldots$. & $\ldots$. & & & $\ldots$. & $\ldots$ & 3 \\
\hline Zona da Mata & & $\ldots$ & E & 8 & & 3 & & $\ldots .$. & & & $\ldots$. & ㄱ. & 11 \\
\hline TOTAL & 11 & 2 & 5 & 3 & & 11 & 73 & 25 & & & 1 & 12 & 188 \\
\hline
\end{tabular}

FONTE - Base de dados da Rede de Tecnologia de Minas Gerais, 2006.

A região que mais demandou informação tecnológica em Minas foi a Região Metropolitana de Belo Horizonte (88), seguindo-se a região Sul (82). Os tipos de informação mais demandados foram os referentes a processos (92), seguindo-se produtos (69) e linha de financiamento (53). Em último lugar no ranking, aparecem as demandas associadas ao campo da metrologia (2). Observa-se que as indústrias precisam de informações que contribuam para a resolução de questões básicas, visto que estão atuando pouco no campo da propriedade intelectual, tendo sido cadastradas apenas quatro solicitações nesta área. Estes dados sinalizam oportunidades e frentes de atuação da RETEC/MG perante seus clientes.

Quanto às microrregiões que demandaram poucas informações, talvez haja uma oportunidade para a RETEC/MG intensificar a divulgação dos seus serviços perante as comunidades empresariais. É importante realizar um estudo mais pontual para verificar por que as regiões utilizam menos os serviços da Rede.

Com relação aos serviços solicitados, a Região Metropolitana de Belo Horizonte encontra-se em primeiro lugar no ranking (71), seguindo-se a

3 Entende-se por matriz toda tabela de números, e variáveis dispostos em filas horizontais (ou linhas) e filas verticais (ou colunas). Se a tabela tiver $\boldsymbol{x}$ linhas e y colunas, dize-se que a matriz é retangular do tipo (ou de ordem) $x$ versus $y$. As linhas são numeradas de cima para baixo e as colunas da esquerda para a direita. 
Centro-Oeste (60) e a Sul (35). Cabe salientar que, das 34 solicitações da Região Metropolitana de Belo Horizonte, referentes a desenvolvimento e melhoria de processo, 30 foram provenientes de projetos de eficiência energética. Daquelas da região Centro-Oeste, 58 foram provenientes do arranjo produtivo local de calçados, estando relacionadas com licenciamento ambiental; e daquelas da região Sul, 17 foram provenientes do arranjo produtivo local de eletroeletrônica. O tipo de serviço mais demandado foi sobre parecer e análise técnica (73), seguindo-se desenvolvimento e melhoria de processo (53) e projetos tecnológicos e de inovação (25); e com os menores índices de solicitações encontram-se capacitação e treinamento de pessoal (2), propriedade intelectual (1) e prospecção tecnológica (1). Aqui, aparece um indicador positivo: uma percentagem de projetos que foram apresentados com foco em inovação. Percebe-se por estes dados que as empresas estão mais atentas às atividades de inovação.

Finalizando a análise dos dados, cabe ressaltar que ainda há problemas na classificação adotada neste processo de transição. Em primeiro lugar, deve-se mencionar que os dados referentes ao campo "objetivo" apresentam 151 demandas classificadas como Outros, o que chamou a atenção da equipe de GIC, pois este número é um ponto crítico no processo de classificação. Com este dado, pode-se levantar algumas questões: será que o demandante está classificando a sua solicitação de forma correta? Será que a equipe de Gestão do Conhecimento e da Informação definiu os objetivos de forma a atender às necessidades do demandante? Para obter respostas a estas perguntas, será preciso analisar individualmente e de forma qualitativa cada demanda. Só assim será possível identificar as lacunas. Em segundo lugar, o campo Abertura de empreendimentos recebeu 121 classificações, mostrando que há um grande interesse dos demandantes em obter informações sobre como abrir seu próprio negócio. Foram classificadas como melhoria tecnológica 86 demandas, o que mostra a preocupação em obter maior qualidade do produto, redução de tempo de fabricação e maior produtividade. Inovação ficou em quarto lugar, com 55 classificações, o que é um indicador positivo, pois se percebe que as empresas estão atentas à necessidade de inovar no mercado em que atuam, na busca de desenvolvimento de produtos e/ou de processos, por meio de recursos financeiros público/privado. A atenção aqui se prende ao conceito e à compreensão do termo inovação tecnológica. É preciso analisar com cautela e, de preferência, in loco, o que os demandantes compreendem e consideram como produto ou processo inovativo. Os objetivos menos solicitados foram os de transferência de tecnologia, (1), patente e marca ( 2 cada uma).

Percebe-se que a RETEC/MG tem um importante papel na oferta e na demanda de informações e de serviços tecnológicos. Estes, depois de classificados e tratados de forma adequada, podem permitir estudos de prospecção tecnológica e estratégica para as regiões de todo o estado de Minas e contribuir com indicadores de apoio à política industrial e de inovação. 


\section{Considerações finais}

Este artigo foi estruturado a partir de um estudo pioneiro e piloto realizado na Rede de Tecnologia de Minas Gerais. Através deste, foi possível perceber que a Rede é um ambiente rico em informações e em serviços tecnológicos provenientes de demandas. Constata-se que a informação com foco tecnológico é de suma importância para as atividades estratégicas de uma organização, pois está carregada de ativos tangíveis e intangíveis de como fazer um produto ou prestar um serviço, e de como manter-se num mercado cada vez mais competitivo e mutável.

Percebe-se que a RETEC/MG está alinhada com as diretrizes da Lei de Inovação na busca pelo estímulo dos centros científicos e técnicos em relação à indústria, através de pesquisas aplicadas, por ser um ambiente de compartilhamento de informação e de suporte tecnológico; por permitir a integração da demanda e da oferta tecnológica entre os diversos agentes econômicos, sociais e institucionais; por prover ações colaborativas entre instituições públicas e privadas voltadas para a política industrial e de inovação; e por mobilizar as empresas no desenvolvimento das competências em pesquisa, tecnologia e inovação, na busca de soluções estratégicas.

A partir deste estudo, observa-se que não se pode desprezar as teorias e metodologias de classificação. O processo de classificação é importante na ordenação e organização das informações que compõem um sistema. O sistema de informação só pode ser bem sucedido se em seu processo contemplar adequadamente a etapa de classificação. Como a RETEC/MG é um sistema em rede e requer a adoção da classificação das demandas, verifica-se que a redefinição das classificações é de extrema relevância.

Com o processo de transição das classificações, observa-se que o demandante passou a ter mais facilidade para classificar as demandas e o supervisor interferiu menos no ajuste dos dados, o que gerou mais confiabilidade. Apesar deste esforço, nota-se ainda que em algumas situações houve dificuldade por parte do demandante na realização da classificação.Talvez esta dificuldade ocorra pela falta de conhecimento do demandante sobre os termos utilizados pela Rede para classificar as demandas, como: propriedade intelectual, insumos, prospecção tecnológica, inovação, dentre outros. Isto ocorre pela falta de um manual de orientação e de um glossário que ajudem os demandantes na atividade de classificar de forma correta e que esclareça o significado de cada termo.

A partir da análise dos dados, averigua-se a situação atual das empresas nas regiões do estado de Minas Gerais como demandantes de informações e serviços tecnológicos. Conclui-se que todo o estado faz uso da Rede, sendo que algumas regiões mais e outras menos. As regiões que mais fazem uso dos serviços são a Região Metropolitana de Belo Horizonte e o Sul de Minas, exatamente aquelas mais desenvolvidas social e economicamente. As regiões que menos solicitaram os serviços são aquelas com baixo aglomerado industrial de micro e pequeno porte. 
Outra constatação é que as indústrias buscam o apoio da Rede para realizar empreendimentos e obter informações sobre desenvolvimento e melhoria de processos e produtos. Porém, quando se analisam os dados sobre a proteção do conhecimento na perspectiva da propriedade intelectual, as indústrias não estão atentas a este item, sendo que a principal causa pode ser o fato de inovarem pouco e também dos custos de proteção ainda serem caros para a micro e pequena indústria.

Cabe ressaltar que as demandas por informação destacam-se em relação às demandas por serviços. Esta afirmação é ponderada pelos dados apresentados no estudo, onde a informação tem se destacado como um recurso estratégico fundamental para o desenvolvimento organizacional e a abertura de empreendimentos. Outro motivo que mantém a informação no ranking em relação aos serviços tecnológicos se dá pela atuação recente do AMITEC. Para ilustrar esta afirmação, toma-se como exemplo o APL de calçados de Nova Serrana em Minas Gerais. No mês de julho de 2006, houve uma ação da Gerência de Meio Ambiente do Sistema FIEMG junto às empresas do Arranjo, na qual o coordenador do programa AMITEC realizou uma divulgação sobre os benefícios que a empresa tem à disposição para a solução de problemas tecnológicos. Após o trabalho de divulgação, houve um aumento representativo das demandas por serviço no mês de agosto e setembro. Talvez em um futuro próximo este tipo de demanda venha a se igualar às demandas por informações. Mas para que esta equivalência ocorra será preciso uma atuação direcionada, constante e forte do AMITEC junto às indústrias.

Outra afirmação é a de que os serviços oferecidos pela Rede têm minimizado os gargalos e contribuído para o desenvolvimento das indústrias mineiras, principalmente aquelas beneficiadas com o programa AMITEC. Quanto aos investimentos provenientes deste programa, percebe-se que as indústrias buscam este apoio para a resolução de questões de base, como: diminuição de gastos com energia, alteração de layout da área de produção, desenvolvimento e melhoria de produtos e processos.

É importante frisar que este trabalho não se encerra com este estudo piloto, configurando-se mais como o início de vários estudos que podem ser realizados a partir dos dados que compõem a Rede, como: ajuste das demandas de 2002 a 2006 à nova proposta de classificação (com este estudo pode-se extrair vários indicadores capazes de retratar as indústrias de Minas com relação às questões tecnológicas); estudos prospectivos sobre estratégias, tecnologias, desenvolvimento e inovação em Minas Gerais; estudo de monitoramento e análise de tendências; estudo sobre as principais informações e serviços demandados durante a atuação da Rede; estudos in loco com empresas beneficiadas com o programa AMITEC; estudos baseados em demandas realizadas por indústrias que compõem a estrutura de APLs, visando identificar suas fragilidades e potencialidades, o que pode permitir um melhor direcionamento dos esforços do sistema FIEMG; estudos qualitativos sobre as demandas classificadas no campo Outros, visando verificar a razão do 
alto índice de classificação neste item; estudo de metodologia para controle e fluxo de conteúdo proveniente de atendimentos informais.

A Rede de Tecnologia de Minas Gerais tem sido um instrumento importante para intermediar as necessidades do demandante, alinhandoas à oferta de serviços disponibilizados. E, com a implementação dos estudos mencionados acima, estes poderão contribuir com 0 desenvolvimento e o crescimento das indústrias, orientando no direcionamento de recursos públicos e privados para questões estratégicas da indústria e subsidiando políticas públicas

O Sistema FIEMG pode ser beneficiado com este estudo, por este permitir o dimensionamento de oportunidades e de ameaças no momento presente e futuro, e orientar a RETEC/MG em suas ações, principalmente, junto às microrregiões que pouco demandam informações e serviços, uma oportunidade que não pode ser desconsiderada.

\section{Referências}

ARAÚJO, Carlos Alberto Ávila. Fundamentos teóricos da classificação. Enc. Bibli: R. Eletr. Bibl. Ci. Inf., Florianópolis, n. 22, 20 sem. 2006. Disponível em: <http://www.encontros-bibli.ufsc.br/Edicao 22/araujo.pdf> Acesso em: 24 jan. de 2007.

ASSOCIAÇÃO Brasileira de Normas Técnicas (ABNT). Disponível em: <http://www.abnt.org.br>. Acesso em: 07 fev. 2008.

BRASIL. Lei $n^{\circ} 10.973$, de 2 de dezembro de 2004. Dispõe sobre incentivos à inovação e à pesquisa científica e tecnológica no ambiente produtivo e dá outras providências. Diário Oficial da União, 03 dez. 2004. Disponível em: <http://www.planalto.gov.br/ccivil 03/ Ato20042006/2004/Lei/L10.973.htm>. Acesso: 10 de maio de 2005.

ESCOSTEGUY, J. P.; CABRAL, A. S. Um modelo sistêmico do processo de inovação tecnológica. In: SIMPÓSIO GESTÃO DA INOVAÇÃO TECNOLÓGICA, 19. Anais... São Paulo, 22 a 25 de outubro de 1996.

FOSKETT, 1996 citado por ARAÚJO, Carlos Alberto Ávila. Fundamentos teóricos da classificação. Enc. Bibli: R. Eletr. Bibl. Ci. Inf., Florianópolis, n. 22, 20 sem. 2006. Disponível em: < http://www.encontrosbibli.ufsc.br/Edicao 22/araujo.pdf> Acesso em: 24 jan. de 2007.

INSTITUTO Brasileiro de Avaliações e Perícias de Engenharia de São Paulo. Disponível em: <www.ibape-sp.com.br>. Acesso em: $07 \mathrm{fev}$. de 2008.

INSTITUTO EUVALDO LODI NACIONAL. Organização da RETEC Nacional: complementação do estudo. Brasília: IEL, 2005. 22 p. (Plano de Negócio).

. Proposta de organização da RETEC Nacional. Brasília:

IEL, 2004. 23 p. 
INSTITUTO NACIONAL DE METROLOGIA, NORMALIZAÇÃO E QUALIDADE INDUSTRIAL - INMETRO. Disponível em: < www.inmetro.gov.br>. Acessado em: 07 de fevereiro de 2008.

KUPFER, D.; TIGRE, P. Prospecção tecnológica. In: CARUSO, L. A.; TIGRE, P. B. (Orgs.). Modelo SENAI de prospecção: documento metodológico. Montevideo: OIT/CINTERFOR, 2004. cap. 2.

MATIAS, P. A. Política de inovação: eixos de intervenção. 2003. 6 p. Disponível em: <http://www.gee.min-economia.pt/resources/users/>. Acesso em: 04 de abril de 2005.

MINISTÉRIO DE CIÊNCIA E TECNOLOGIA. Secretaria Técnica. Fundo Verde-Amarela. Centro de Gestão e Estudos Estratégicos: ciência, tecnologia e inovação. 2003.2 Disponível em: <http://www.mct.gov.br/Fontes/Fundos/Documentos/CTFVA>. Acesso em: 29 de abril de 2005.

MUESER, 1985 citado por ESCOSTEGUY, J. P.; CABRAL, A. S. Um modelo sistêmico do processo de inovação tecnológica. In: SIMPÓSIO GESTÃO DA INOVAÇÃO TECNOLÓGICA, 19. Anais... São Paulo, 22 a 25 de outubro de 1996.

ORGANIZAÇÃO Mundial de Propriedade Intelectual . Disponível em: <www.wipo.int/>. Acesso em: 07 de fevereiro de 2008.

ROMERO, C. C. Inovação tecnológica: lei de inovação tecnológica: críticas e contribuições. [São Paulo]: Senac, [200-?]. Disponível: <http://www.senac.br/informativo/BTS/282/boltec282d.htm>. Acesso em: 10 de maio de 2005.

SILVA, J. F. Estudo de necessidade de informação tecnológica dos setores industriais brasileiros: análise crítica e proposições, 2000. Dissertação (Mestrado em Ciência da Informação) - Universidade Federal de Minas Gerais, Belo Horizonte, 2000. 


\section{ANEXO A - Significados ou conceitos dos tipos de serviços e informações}

O significado dos tipos de informação e serviços demandados à RETEC/MG são compreendidos neste trabalho como:

- Insumo: usado para designar um bem de consumo que é utilizado na produção de um outro bem. É a combinação de fatores de produção, diretos (matérias-primas) e indiretos (mão-de-obra, energia, tributos), que entram na elaboração de certa quantidade de bens ou serviços.

- Linhas de financiamento: instrumentos e agentes de incentivo e fomento às ações de ciência e tecnologia no âmbito nacional e internacional.

- Normas técnicas ${ }^{4}$ : documentos estabelecidos por consenso e aprovado por um organismo reconhecido que fornece, para uso comum e repetitivo, regras, diretrizes ou características para atividades ou seus resultados, visando à obtenção de um grau ótimo de ordenação em um dado contexto.

- Operações administrativas: estão relacionadas com o gerenciamento das atividades da organização, como por exemplo: gerenciar equipes, elaborar estatutos, administrar o fluxo de caixa, acompanhar a execução orçamentária, administrar o patrimônio da organização, estabelecer normas e regras administrativas, dentre outras ações.

- Processo: conjunto seqüencial, sistematizado e peculiar de ações que objetivam atingir uma meta. É usado para criar, inventar, projetar, transformar, produzir, controlar, manter e usar produtos ou sistemas.

- Produto: qualquer coisa que possa ser oferecida a um mercado que possa satisfazer um desejo ou uma necessidade. Contudo é muito mais do que apenas um objeto físico, é o pacote completo de benefícios ou satisfação que os compradores percebem que eles obterão, se adquirirem o produto. É a soma de todos os atributos físicos, psicológicos, simbólicos e de serviço.

- Propriedade intelectual $\left.\right|^{5}$ : é a soma dos direitos relativos às obras literárias, artísticas e científicas, às interpretações dos artistas intérpretes e às execuções dos artistas executantes, aos fonogramas e às emissões de radiodifusão, às invenções em todos os domínios da atividade humana, às descobertas científicas, aos desenhos e modelos industriais, às marcas industriais, comerciais e de serviço, bem como às firmas

4 Associação Brasileira de Normas Técnicas (ABNT). Disponível em: <http://www.abnt.org.br>. Acessado em: 07/02/08.

5 Organização Mundial de Propriedade Intelectual . Disponível em: < www.wipo.int/>. Acessado em: 07/02/08. 
comerciais e denominações comerciais, à proteção contra a concorrência desleal e todos os outros direitos inerentes à atividade intelectual nos domínios industrial, científico, literário e artístico.

- Metrologia ${ }^{6}$ : ciência que abrange todos os aspectos teóricos e práticos relativos às medições, qualquer que seja a incerteza em qualquer campo da ciência ou tecnologia.

- Quanto ao significado dos tipos de serviços entende-se por:

- Gestão da qualidade: é a construção de uma estratégia de administração orientada a criar consciência de qualidade em todos os processos organizacionais.

- Capacitação e treinamento de pessoal: está relacionado com a formação e desenvolvimento profissional e pessoal do corpo técnico e administrativo da organização.

- Desenvolvimento e melhoria de processo e de produto: é a gestão da organização, onde se busca a análise tanto para o nível gerencial (também chamados processos-chave ou macro-processos do negócio e do produto) como também para o nível operacional da empresa. Ao buscar o desenvolvimento e melhoria de processos e de produto torna-se necessária a atenção com relação às suas atividades, que podem ser: com relação ao primeiro, elaboração de mapas gerenciais dos processos-chave da organização, analisando e identificando suas entradas e saídas, a relação cliente-fornecedor dentro da cadeia de valor do negócio, o fluxo de atividades dentro de cada processo e os indicadores de desempenho relacionados ao monitoramento dos resultados e performance de cada um; quanto ao segundo, desenvolvimento do design, das plantas, planejamento e controle das vendas, gestão do cliente, produção, matéria-prima, dentre outros.

- Parecer ${ }^{7}$ : opinião, conselho ou esclarecimento técnico emitido por um profissional legalmente habilitado sobre assunto de sua especialidade.

- Análise técnica ${ }^{8}$ ou análise gráfica, é uma abordagem que utiliza gráficos como ferramenta principal para determinar o melhor momento para comprar e vender ativos. Em complemento à utilização de gráficos, a análise técnica inclui também uma série de teorias sobre como acontecem os movimentos do mercado.

6 Instituto Nacional de Metrologia, Normalização e Qualidade Industrial (INMETRO). Disponível em: < www.inmetro.gov.br>.Acessado em: 07/02/08.

7 Instituto Brasileiro de Avaliações e Perícias de Engenharia de São Paulo. Disponível em: $<$ www.ibape-sp.com.br>.

8 Instituto Brasileiro de Avaliações e Perícias de Engenharia de São Paulo. Disponível em: $<$ www.ibape-sp.com.br>. 
- Prospecção tecnológica: organização e estruturação, por meio de uma reflexão coletiva, dos desafios futuros e, eventualmente, da avaliação das opções estratégicas. É entendida como um meio sistemático de mapear desenvolvimentos científicos e tecnológicos futuros capazes de influenciar de forma significativa uma indústria, a economia ou a sociedade como um todo. Diferentemente das atividades de previsão clássica, que se dedicam a antecipar um futuro suposto como único, os exercícios de prospecção são constituídos a partir da premissa de que são vários os futuros possíveis (KUPFER; TIGRE, 2004). 